\title{
НАУНОВЕДЕНИЕ
}

EESTI NSV TEADUSTE AKADEEMIA TOIMETISED, 28. KOIDE KEEMIA. 1979, NR. 1

ИЗВЕСТИЯ АКАДЕМИИ НАУК ЭСТОНСКОИ ССР. ТОМ 28 Химия. 1979, № 1

Хелле МАРТННСОН

удК 001.89

\section{ФОРМИРОВАНИЕ НАУЧНЫХ КАДРОВ НИИслаНцев (1958-1975 гг.)}

\section{(Представлена О. Кирретом)}

В науковедении в последнее время все больше и больше используются методы количественного статистического анализа. Анализ динамики количественных параметров, подлежащих подсчету и описывающих развитие как науки в целом, так и ее отдельных отраслей, учреждений, коллективов ученых, позволяет хотя бы приблизительно оценивать продуктивность научных коллективов, динамику их развития, сравнивать результативность работы отдельных групп ученых или же делать некоторые прогнозирующие выводы о различных аспектах развития науки как сферы человеческой деятельности.

Настоящая работа, которая входит в серию статей $\left[{ }^{1-5}\right]$, описывающих развитие научных коллективов химического профиля Эстонской ССР, посвящена НИИсланцев (Миннефтехимпром СССР) в период 1958-1975 гг. Рассмотрению подлежали показатели, характеризующие динамику кадрового потенциала института.

\section{Организация института}

Научно-исследовательский институт сланцев был организован в г. Кохтла-Ярве по инициативе Правительства и ЦК КПЭ 1 июня 1958 г. с подчинением Совнархозу ЭССР во исполнение решений майского Пленума ЦК КПСС о развитии химической промышленности []. Институт создавался на базе бывшего ВНИИ по переработке сланцев (ВНИИПС) в Ленинграде и исследовательского отдела подлежавшего реорганизации Проектного и научно-исследовательского института Министерства местной и сланцехимической промышленности ЭССР (ПНИИ) в Таллине, проектная часть которого вылилась в Эстпромпроект.

Основными задачами института (во время организации назывался НИИ по добыче и переработке сланцев) были:

- изучение сырьевой базы сланцевой промышленности;

- разработка новых и интенсификация существующих экономически эффективных методов добычи и переработки сланцев, переработка и улучшение качества получаемой при этом продукции;

- изыскание способов использования побочных продуктов сланцепереработки, утилизации и очистки промышленных стоков и газовых выбросов, борьба с коррозией;

- технико-экономические разработки в области технологии сланцев.

Эти направления являются для института профилирующими и по сей день. В декабре 1965 г. горные лаборатории с разрабатываемой ими тематикой и базой были переданы тресту «Эстонсланец», а основное 
внимание НИИсланцев сконцентрировал на разработке теоретических, технологических и технико-экономических проблем в области переработки сланцев и использовании получаемых при этом химических и топливных продуктов.

В связи с реорганизацией руководства промышленности по отраслевому принципу в стране институт по решению Совета Министров ӘССР был передан (в январе 1966 г.) в ведение Министерства нефтеперерабатывающей и нефтехимической промышленности Союза ССР и в июле 1966 г. подчинен Главному управлению сланцеперерабатывающей промышленности названного министерства.

\section{Динамика научных кадров}

При организации института его штат был определен в 110 человек. Хотя при комплектовании института из ВНИИПС ему было передано 38 и из ПНИИ - 16 человек, в действительности в Кохтла-Ярве обосновались лишь единичные сотрудники. Таким образом, институт вынужден был сам укомплектовывать свои кадры, в первую очередь, - за счет специалистов сланцевой промышленности и выпускников вузов. Для этого институту пришлось в течение нескольких лет приложить немало усилий из-за ряда трудностей, возникших в связи с местонахождением института на периферии, относительно низкими окладами и т. д. Но, несмотря на трудности, к концу 1960 г. институт был в основном укомплектован кадрами (122 сотрудника) и мог приступить к решению научных задач.

Динамика общего числа работников, научных сотрудников, специа-

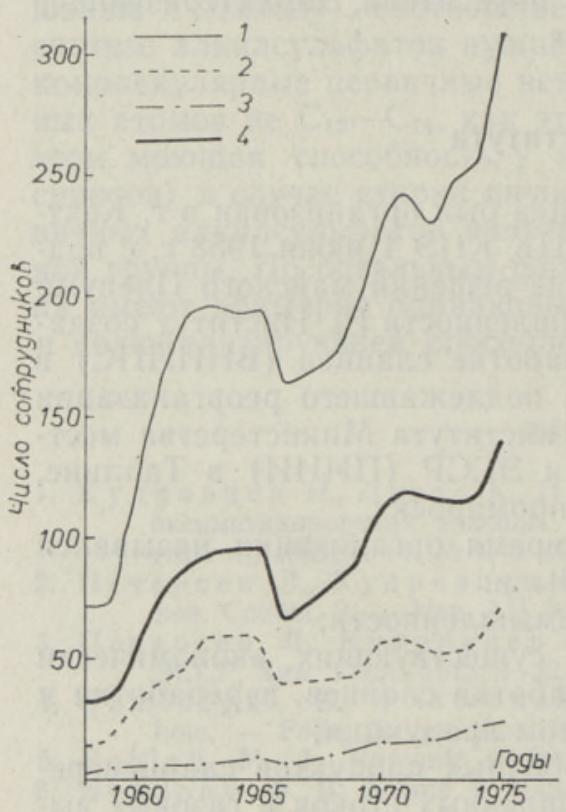

Рис. 1. Рост численности сотрудников НИИсланщев. 1 - все сотрудники, 2 научные сотрудники, 3 - сотрудники с учеными степенями, 4 - сотрудники с высшим образованием,

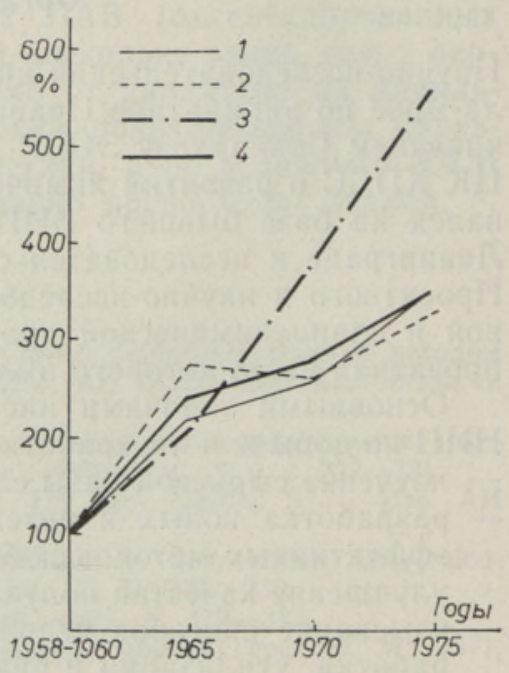

Рис. 2. Темпы прироста среднегодовой численности сотрудников НИИсланцев. (Обозначения те же, что на рис. 1), 
Соотношение числа научных сотрудников без ученых степеней и числа научных сотрудников с учеными степенями и число инженерно-технического персонала, приходящееся на одного научного сотрудника

\begin{tabular}{l|l|l|l|l}
\hline Показатели & 1960 & 1965 & 1970 & 1975 \\
\hline
\end{tabular}

Число научн, сотр. без уч. степеней на 1 научн. сотр. со степенью

Число инж.-техн. персонала на 1 научн. сотр.

$\begin{array}{llll}5,4 & 5,6 & 2,7 & 2,0 \\ 2,0 & 1,6 & 2,2 & 2,6\end{array}$

таблица 2

Темпы прироста среднегодовой численности всех сотрудников, научных сотрудников, сотрудников со степенями, сотрудников с высшим образованием и научных публикаций, \%

\begin{tabular}{l|c|c|c|c}
\hline \multicolumn{1}{c|}{ Показатели } & \multicolumn{4}{|c}{ Годы } \\
\cline { 2 - 5 } & $1958-1960$ & 1965 & 1970 & 1975 \\
\hline Прирост общего количества сотрудников & 100 & 216,9 & 250,6 & 347,2 \\
Прирост научных сотрудников & 100 & 271,9 & 258,1 & 327,2 \\
Прирост сотрудников с учеными степенями & 100 & 209,3 & 375,0 & 558,1 \\
Прирост сотрудников с высшим образованием & 100 & 237,5 & 275,0 & 347,5 \\
Прирост числа научных публикаций & 100 & 369,6 & 336,7 & 431,6
\end{tabular}

листов с высшим образованием и сотрудников с учеными степенями за 1958-1975 гг. приведена на рис. 1 [7]. Он показывает, что прирост численности первых трех групп сотрудников был постоянным и быстрым до 1965 г., а спад в 1965-1966 гг. был вызван отделением горных лабораторий от института. Тенденция постоянного увеличения числа сотрудников сохранялась в 1965-1970 гг. и продолжалась до 1975 г. Скачок вверх в 1975 г. связан с переводом исследовательской группы (46 чел.) из центральной лаборатории Сланцеперерабатывающего комбината им. В. И. Ленина в состав института.

Интересно отметить, что в результате этого общая численность сотрудников НИИсланцев в 1975 г. превышала этот показатель для Института химии АН ЭССР (ИХ) - до тех пор самого крупного научного учреждения химического профиля в республике.

В то время, как рост первых трех параметров был довольно быстрым и постоянным, увеличение числа сотрудников, имеющих ученые степени, происходило гораздо медленнее. Лишь к 1968 г. число кандидатов наук достигло 10, в 1970 г. была защищена первая докторская диссертация.

В табл. 1 приведено соотношение числа научных сотрудников без ученых степеней и числа научных сотрудников, имеющих ученые степени. В 1965 г. это соотношение было очень неблагоприятным: 5,6:1, к 1975 г. оно достигло $2: 1$, что можно считать уже нормальным. Так, на химическом отделении Тартуского гос. университета (ТГУ) и в ИХ это соотношение в 1965 г. составляло $3,3: 1$ и $2,1: 1$, а в 1975 г. $-2,8: 1$ и $1,8: 1$, соответственно, для СССР в целом - 3,5:1 в 1965 г. и $2,7: 1$ в 1970 г. Из этого следует, что в НИИсланцев базис прироста числа сотрудников с учеными степенями в ближайшие годы достаточный, и темпы прироста их числа могут возрастать и впредь. Кстати, для НИИсланцев характерна за весь период несколько меньшая доля научных сотрудников среди всех работников, чем в ИХ и ТГУ. 
При рассмотрении темпов прироста среднегодовой численности всех категорий сотрудников НИИсланцев (табл. 2, рис. 2) выясняется, что темпы прироста числа сотрудников возрастали даже в период 19651970 гг., когда, по вышеупомянутым причинам, имело место снижение абсолютной численности персонала института, и лишь темпы прироста числа научных сотрудников замедлились к 1970 г. С 1970 г. темпы прироста общей численности работников, научных сотрудников и специалистов с высшим образованием были почти равными, а темпы прироста сотрудников с учеными степенями с 1965 г. очень заметно увеличились. К 1975 г. численность всех сотрудников, научных сотрудников и специалистов с высшим образованием возросла примерно в 3,5 раза; наблюдалось 2 удвоения: для общего количества специалистов - через 3 года и 15 лет, для научных сотрудников - через 3 и 2 года, для специалистов с высшим образованием - через 3 года и 15 лет. Численность сотрудников с учеными степенями возросла за это время в 5,6 раза (2 удвоения: первое - через 3 года и второе - через 8 лет).

Темпы прироста всех показателей кадрового составляющего научного потенциала НИИсланцев почти совпадают с показателями для ТГУ, а по сравнению с показателями ИХ они почти в 2 раза ниже (следует помнить, что основные химико-технологические лаборатории НИИсланцев развивались слабее, чем другие подразделения). По-видимому, это было обусловлено тем, что в базисный пернод (1947-1950) численность сотрудников ИХ была почти в 3 раза ниже показателя для НИИсланцев (в 1958-1960). Опережающие темпы прироста сотрудников с учеными степенями совпадают с тенденциями для ИХ, ТГУ и республики в целом.

Если же рассматривать темпы прироста среднегодовой численности всех групп сотрудников НИИсланцев по отношению к предыдущему периоду (рис. 3), выясняется, что, несмотря на значительный спад в 1965-1970 гг., обусловленный разделением института, темпы прироста в $1971-1975$ гг. были положительными, в противоположность темпам прироста в ТГУ и ИХ, а также показателям научных кадров республики в целом [8]. Медленное, но постоянное возрастание темпов прироста среднегодовой численности всех групп сотрудников НИИсланцев в последнее пятилетие свидетельствует о постоянном укреплении кадрового потенциала института.

В институте относительно высок процент сотрудников с высши м обр азов ание м, составлявший в 1965 г. 49,2, в 1970 г. - 49,3 и в 1975 г. - 45,0\% от всех сотрудников, но все же этот показатель был ниже показателя для ИХ, который к 1975 г. равнялся 64\%. За рассматриваемые 18 лет в институте проработал по меньшей мере 1 год 291 человек с высшим образованием, а в ИХ за 28 лет - 278 человек. Из этого следует, что текучесть кадров с высшим образованием в НИИсланцев при их меньшем абсолютном числе была гораздо выше, чем в ИХ.

Из специалистов, работавших и работающих в НИИсланцев, 114 человек $(39,1 \%)$ - выпускники Таллинского политехнического института (ТПИ), $34(11,7 \%)$ - ТГУ, других вузов ЭССР - 4 человека $(1,4 \%)$; 123 человека $(42,3 \%)$ окончили вузы в других городах СССР, до войны в СССР получили образование 12 человек $(4,1 \%)$, в вузах буржуазной Эстонии учились 4 человека $(1,4 \%)$. В НИИсланцев удельный вес специалистов, окончивших вузы в других городах Союза ССР, гораздо выше, чем в ИХ $(13,3 \%)$ и ТГУ $(4,7 \%)$. Это обусловлено, очевидно, местонахождением института в сланцевом бассейне, его подчинением всесоюзному ведомству, а также тем, что ТПИ фактически в середине 1960-х гг. прекратил подготовку химиков-технологов по переработке 
Рис. 3. Темпы роста среднегодовой численности всех сотрудников (1), научных работников (2), кандидатов + докторов наук (3) и сотрудников с высшим образованием (4) НИИсланцев по сравнению с предыдущим периодом.

топлив (сланцев) и основной контингент его выпускников были женщины.

За неимением исходных данных нам не удалось установить, в какой степени работа специалистов с высшим образованием соответствовала поставленным перед ними научным задачам, однако спектр специальностей по высшему образованию (табл. 3) чрезвычайно пестрый. Мы насчитали по меньшей мере 68 специальностей, среди которых были такие, как агрономия и лесоинже-

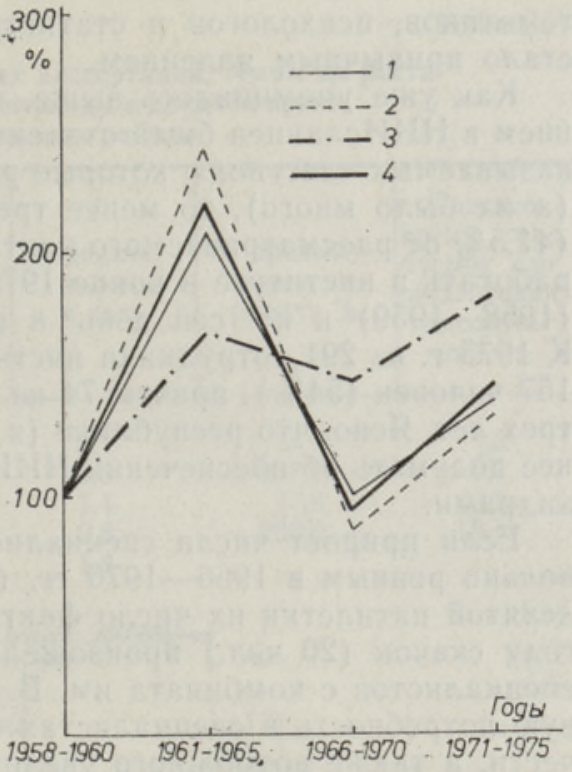
нерное дело, технология продовольственных продуктов, машины и аппараты текстильной промышленности, судовые машины и механизмы и т. д. Сравнивая специальности с задачами, стоявшими перед институтом в отдельные периоды, мы можем утверждать, что по крайней мере половине специалистов, проработавших в институте более одного года, пришлось в ходе работы переквалифицироваться.

Конечно, разрабатываемые НИИсланцев проблемы обусловливают подбор специалистов по значительно большему числу специальностей, чем в ИХ или ТГУ: например, в горном отделении, в лаборатории экономики и НОТ, в секторе коррозии, секторе автоматизации и АСУ работают и работали специалисты разных нехимических специальностей. Кроме того, в современную эпоху интеграции наук участие физиков, ма-

Таблица 3

Распределение специалистов с высшим образованием по группам специальностей

Группы специальностей

Разработка месторождений полезных ископаемых (итого работало в институте по 5 специальностям)

Химическая технология (итого по 11 специальностям)

Химия (в университетах)

Технология продовольственных продуктов (итого по 4 специальностям)

Лесоинженерное дело, технология древесины, целлюлозы и бумаги (итого по 3 специальностям)

Разные специальности в университетах (итого по 9 специальностям)

Сельское и лесное хозяйство (итого по 4 специальностям)

Экономика (итого по 7 специальностям)

Педагогические специальности (итого по 5 специальностям)

Электронная техника и автоматика (итого по 5 специальностям)

Прочие (итого по 14 специальностям)

Итого по 68 специальностям:
13,4

39,9

7,9

1,7

1,7

8,2

2,1

9,3

4,5

3,4

7,9

100,0 
тематиков, психологов и статистиков в работе коллективов химиков стало привычным явлением.

Как уже упоминалось выше, текучесть кадров с высшим образованием в НИИсланцев была относительно высокой. Если не учитывать так называемых «летунов», которые работали в институте менее одного года (а их было много), то менее трех лет в нем проработал 121 человек ( $41,5 \%$ от рассматриваемого контингента, 47 человек из них продолжали работать в институте в конце 1975 г.), а с периода основания ннститута (1958-1959) и по сей день в нем работают лишь 24 специалиста. К 1975 г. из 291 сотрудника институт покинули по различным причинам 157 человек $(54 \%)$, причем 74 из них проработали в НИИсланщев менее трех лет. Ясно, что республике (в частности, ТПИ) следовало бы серьезнее подумать об обеспечении НИИсланцев специально подготовленными кадрами.

Если прирост числа специалистов с высшим образованием был довольно ровным в 1966-1970 гг. (8-12 чел. в год), то в первые 4 года девятой пятилетки их число фактически не увеличилось, а в последнем году скачок (20 чел.) произошел в основном за счет перевода группы специалистов с комбината им. В. И. Ленина. Тем не менее, среднегодовую потребность в специалистах с учетом выбытия по возрасту и текучести, а также возможного увеличения штатов института легко определить. Эти данные более серьезно следовало бы учитывать и Министерству высшего и среднего специального образования республики при планировании подготовки специалистов и распределении выпускников ТПИ. Конечно, здесь и впредь будут иметь место определенные трудности, так как промышленный центр Кохтла-Ярве мало привлекает молодежь.

Необходимо отметить, что за рассматриваемый период в НИИсланцев из ТПИ было направлено только 14 химиков-технологов (впервые в 1968 г.), 10 остались в нем работать, но через $2-3$ года 4 из них покинули институт. По направлению ТГУ за 1960-1962 гг. институт получил 7 химиков, 5 из которых остались здесь работать. Таким образом, за 18 лет НИИсланцев получил из вузов нашей республики в плановом порядке лишь 21 специалиста-химика, 15 из которых остались в нем на постоянную работу.

В НИИсланцев за все время его существования соотношение инженерно-технического персонала и научных сотрудников было довольно благоприятным (табл. 1). В 1975 г. на 1 научного сотрудника приходилось уже 2,6 чел. инженерно-технического персонала, что очень близко к предполагаемому оптимальному значению для химических институтов: $3: 1$ [9]. Обусловлено это преимущественно технологическим характером проводимых исследований - сооружение стендов и опытных установок и работа на них требует больше усилий технического персонала, чем специалистов с высокой научной квалификацией. Такое благоприятное соотношение должно было бы, в свою очередь, содействовать и более высокой научной отдаче рассматриваемого коллектива, на чем мы остановимся ниже.

Так как НИИсланцев не имеет своей аспирантуры, основной контингент специалистов высшей квалификации подготовляется в аспирантуре ТПИ - из 27 аспирантов (11 из них окончили аспирантуру незадолго до поступления на работу в НИИсланцев) $12(44,5 \%)$, в институтах Ленинграда $(9$, или $33,3 \%)$ и ИХ (6, или $22,2 \%)$. Всего за рассматриваемый период при НИИсланцев целиком или частично было подготовлено и защищено 32 кандидатские и 2 докторские диссертации (см. табл. 4). Среднегодовое количество защищенных диссертаций также довольно скромное: к 1971-1975 гг. оно составляло 3 работы в год. 
Количество защищенных кандидатских диссертаций, темпы их роста по отношению к предыдущему периоду и среднее время, требуемое для завершения работы

\begin{tabular}{|c|c|c|c|c|}
\hline Годы & $\begin{array}{l}\text { Количество } \\
\text { защищенных } \\
\text { диссертаций }\end{array}$ & $\begin{array}{c}\text { Среднее } \\
\text { кол-во } \\
\text { в год }\end{array}$ & $\begin{array}{c}\text { K предыду- } \\
\text { щему пе- } \\
\text { риоду, \% }\end{array}$ & $\begin{array}{c}\text { Среднее } \\
\text { время, тре- } \\
\text { буемое для } \\
\text { подготовки } \\
\text { диссерта- } \\
\text { ции, 2 }\end{array}$ \\
\hline
\end{tabular}

$\begin{array}{crrrr}1958-1960 & 2 & 0,7 & - & 4,0 \\ 1961-1965 & 9 & 1,8 & 257,1 & 5,3 \\ 1966-1970 & 7 & 1,4 & 77,8 & 8,4 \\ 1971-1975 & 14 & 2,8 & 200,0 & 10,1 \\ \text { Итого: } & 32 & 1,8 & & \end{array}$

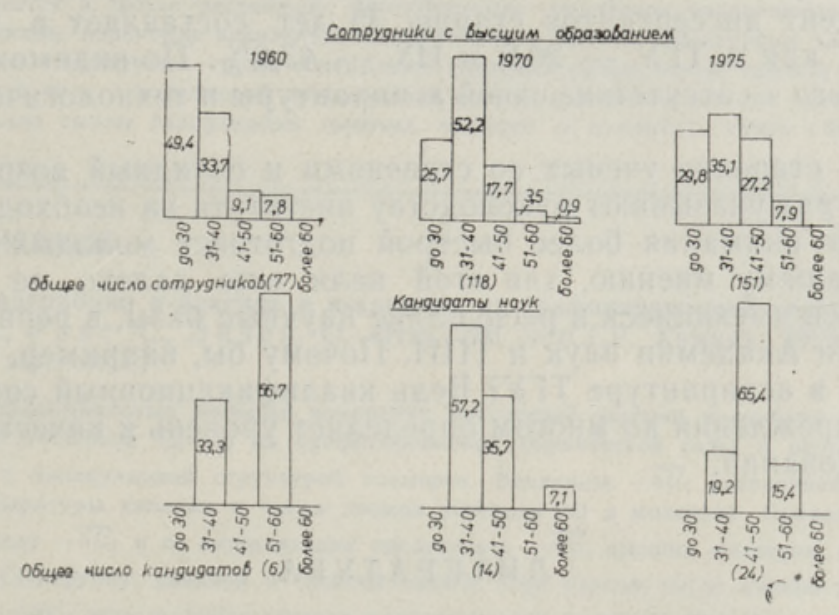

Рис. 4. Возрастное распределение (\%) сотрудников с высшим образованием и кандидатов наук НИИсланцев.

Среднее время, требуемое для завершения диссертации с момента поступления диссертанта на работу в НИИсланцев, постоянно растет - от 4 лет в 1958-1960 гг. до 10 лет в 1971-1975 гг. В ТГУ и ИХ наблюдалась такая же тенденция: в первом оно возросло с 4 лет в 1956-1960 гг. до 7,1 года в $1971-1975$ гг., во втором - с 6,6 года в $1951-1955$ гг. до 9,6 года в 1971-1975 гг. Темпы прироста количества защищенных диссертаций за последние 5 лет увеличились, в противовес ИХ и ТГУ.

Необходимо отметить, что 2 докторские диссертации были завершены сотрудниками НИИсланцев в более быстрые сроки, чем в ИХ, - в 7 и 13 лет. Однако количество докторов в НИИсланцев чрезвычайно скромное (2), тем более, что 1 доктор в 1975 г. покинул его.

Что касается воз растной структуры сотрудников НИИсланцев с высшим образованием и учеными степенями (рис. 4), то можно сказать, что происходит постепенное старение специалистов с высшим образованием: если в 1960 г. в возрасте 40 лет было $83,1 \%$ от всех специалистов, то к 1970 г. их доля снизилась до $72,9 \%$, к 1975 г. - уже до $64,9 \%$, а удельный вес сотрудников в возрасте от 40 до 50 и 60 лет соответственно увеличился.

Такое старение, являющееся в какой-то степени неизбежным, должно вести и к снижению творческой активности коллектива, так как, по мне- 
нию многих авторитетов, «потолок» творческой активности достигается учеными в возрасте до 40 лет. Кстати, такая тенденция наблюдается и в ИХ: ученых до 40 лет в нем было в соответствующие годы $75,9,72,9$ и $63,5 \%$.

Еще больше бросается в глаза старение сотрудников с учеными степенями. Ученые до 30 лет в этой группе отсутствуют во все рассматриваемые годы, а число ученых до 40 лет упало в 1970 г. с 57,2 до $19,2 \%$, в 1975 г. с увеличением числа ученых до 60 лет с 35,7 до 80,8\%, соответственно. Эта тенденция аналогична для ИХ и ТГУ, однако в них она проявляется медленнее.

В возрастном распределени и диссертантов наблюдается следующее: 4 работы $(12,5 \%)$ были защищены диссертантами в возрасте моложе 30 лет, 3 из них защитили диссертации сразу после окончания аспирантуры. 10 диссертантов $(31,3 \%)$ были в возрасте $31-35$ лет, $8(25,0 \%)-36-40$ лет и $10(31,3 \%)$ - старше 40 лет. По сравнению с ТГУ и ИХ, средний возраст диссертантов в НИИсланцев значительно выше: процент диссертантов старше 35 лет составляет в нем $56,2 \%$, в то время, как в ТГУ $-20,8$ и ИХ - 43,6\%. По-видимому, главные причины этого - отсутствие своей аспирантуры и технологический уклон работ.

Быстрое старение ученых со степенями и солидный возраст диссертантов еще раз указывают руководству института на необходимость уделять больше внимания более быстрой подготовке молодых кандидатов наук. По нашему мнению, для этой цели еще далеко не достаточно используются имеющиеся в республике научные базы, в первую очередь, возможности Академии наук и ТПИ. Почему бы, например, не готовить кандидатов в аспирантуре ТГУ? Ведь квалификационный состав кадров научного учреждения во многом определяет уровень и качество проводимых исследований.

\section{ЛИТЕ РА Т Р А}

1. Мартинсон Х. Движение научных кадров химического отделения Тартуского государственного университета и их продуктивность по научным публикациям. - Уч. зап, Тартуского ун-та, 1976, вып, 384. Труды по химии, т. Х (2), c. $128-151$.

2. М а р тин сон Х. Анализ кадрового потенщиала Института химии АН ЭССР с 1947 по 1975 г, - Изв. АН ЭССР, Хим., 1978, т. 27, № 1, с. 59-73.

3. М а р тин сон X, Анализ научной продуктивности, цитируемости работ и финансового обеопечения Института химии АН СССР с 1947 по 1975 г. - Изв. АН ЭССР, Хим., 1978 , т. 27 , № 2, с. $123-136$.

4. М а р ти н со о $\mathrm{X}$. Анализ цитируемости научных лубликаций химиков Эстонской CСР. - В кн.: Вопросы истории Тартуского университета. (Материалы комиссии истории университета), т. V. Тарту, 1977, с. 185-196.

5. М ар тин сон X. Анализ цитируемости научных публикаций как способ определения значимости и распространения результатов исследований. (По материалам химической науки Әстонской (СР). - В кн.: Из истории естествознания и техники Прибалтики, т. VI. Рига (в печати).

6. НИИсланцев. Техническая библиотека № 01783. Доклад о деятельности института за 10 лет (19518-1968) (рукопі.).

7. Годовые и статистические отчеты НИИсланцев. Материалы отдела кадров НИИсланцев (рукоп.).

8. Martinson, K. Teadlane ja teaduslik publikatsioon Eesti NSV-s. Tallinn, 1973.

9. НОТ в институте. Кнев, 1968.
Институт химии
Академии наук Эстонской ССР
Поступила в редакцию 10/III 1978 